\title{
Improving wait times to care for individuals with multimorbidities and complex conditions using value stream mapping
}

\author{
Tara Sampalli ${ }^{1,2,3^{*}}$, Michel Desy $^{4}$, Minakshi Dhir ${ }^{1,3}$, Lynn Edwards ${ }^{3}$, Robert Dickson ${ }^{1}$, \\ Gail Blackmore ${ }^{4}$
}

\begin{abstract}
Background: Recognizing the significant impact of wait times for care for individuals with complex chronic conditions, we applied a LEAN methodology, namely - an adaptation of Value Stream Mapping (VSM) to meet the needs of people with multiple chronic conditions and to improve wait times without additional resources or funding.

Methods: Over an 18-month time period, staff applied a patient-centric approach that included LEAN methodology of VSM to improve wait times to care. Our framework of evaluation was grounded in the needs and perspectives of patients and individuals waiting to receive care. Patient centric views were obtained through surveys such as Patient Assessment of Chronic Illness Care (PACIC) and process engineering based questions. In addition, LEAN methodology, VSM was added to identify non-value added processes contributing to wait times.

Results: The care team successfully reduced wait times to 2 months in 2014 with no wait times for care anticipated in 2015. Increased patient engagement and satisfaction are also outcomes of this innovative initiative. In addition, successful transformations and implementation have resulted in resource efficiencies without increase in costs. Patients have shown significant improvements in functional health following Integrated Chronic Care Service (ICCS) intervention. The methodology will be applied to other chronic disease management areas in Capital Health and the province.

Conclusion: Wait times to care in the management of multimoribidities and other complex conditions can add a significant burden not only on the affected individuals but also on the healthcare system. In this study, a novel and modified LEAN methodology has been applied to embed the voice of the patient in care delivery processes and to reduce wait times to care in the management of complex chronic conditions.

Keywords: Wait Times, Multimorbidities, LEAN Methodologies, Patient Experience

Copyright: (C) 2015 by Kerman University of Medical Sciences

Citation: Sampalli T, Desy M, Dhir M, Edwards L, Dickson R, Blackmore G. Improving wait times to care for individuals with multimorbidities and complex conditions using value stream mapping. Int J Health Policy Manag. 2015;4(7):459-466. doi:10.15171/ijhpm.2015.76
\end{abstract}

Article History:

Received: 15 December 2014

Accepted: 31 March 2015

ePublished: 5 April 2015

View Video Summary

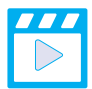

*Correspondence to:

Tara Sampalli

Email: tara.sampalli@cdha.nshealth.ca

\section{Key Messages}

Implications for policy makers

- This paper has applied a modified Value Stream Mapping (VSM) approach to improve a highly prevalent problem in the healthcare system, namely, wait times to care in a complex care setting.

- This paper describes standardized tools such as Patient Assessment of Chronic Illness Care (PACIC), VSM and Referring Satisfaction Survey to embed key stakeholder perspectives in chronic disease management.

- The study has shown a method to improving care without increasing costs to care.

Implications for public

Waiting to receive care has become a common occurrence in the Canadian system. This can have a negative impact on how individuals experience care. Individuals who have multiple medical problems or those that have not received a diagnosis go through significant physical and mental health distress during these wait times. In this study, we have used a new way of reducing wait times and improving care for complex problems. We used a method that creates a visual map of a patient's journey and identifies steps that do not add value to them. We have used a method called Value Stream Mapping (VSM) in a care facility that treats people with complex problems and with high wait times to care. By including patients' views and by mapping their journey, we have been able to remove wait times to care. We have added steps that increase value to care without increase in costs.

\section{Introduction}

Wait times have become a prevalent characteristic of the Canadian healthcare experience. Patients who have delayed access to relevant care, particularly those with complex conditions end up becoming high users of emergency services $(1,2)$. A patient with chronic illness and multimorbidities requires a range of health services delivered by primary care, community care, acute care, professionals and specialists (1). Recent evidence shows that a higher percentage of younger demographics are being impacted with multimorbidities $(3,4)$. The increasing number of individuals accessing multiple services and specialists requires a system that can 
better respond to their needs in a timely and effective manner. The burden of chronic conditions is on the rise resulting in bottlenecks in various parts of our healthcare system (5). Nova Scotia is also home to the highest proportion of people living with disabilities caused by chronic conditions $(6,7)$. As Nova Scotia's largest health services provider, Capital Health serves over 400,000 residents and provides specialist services to all of Atlantic Canada. The rates of chronic diseases and risk factors within Capital Health are very similar to provincial rates $(5,8)$. Primary Health Care (PHC) has identified improving care to vulnerable and hard to reach patients as a priority area for 2014-7 $(5,8,9)$. A key action step within this goal is to provide timely and relevant access to care for population with high needs. A sub-goal of this action step is to remove wait times for complex and chronic illness care. Through an opportunity from the Canadian Foundation for Healthcare Improvement, Capital Health has developed and implemented a methodology to evaluate and improve delivery processes in the management of chronic conditions and multimorbidities with a goal to enhance care experiences for affected individuals. Four service areas participated in the chronic disease management initiative and the Value Stream Mapping (VSM) initiative described in this paper is part of this broader study $(10,11)$. In this paper, a modified VSM that was applied to reduce wait times to care in the management of complex chronic conditions is described.

\section{Background of the problem}

Traditionally, reducing wait times has been related to increasing funding for programs or services, which is often not feasible. LEAN techniques have been applied quite effectively as a means to address wait time issues without additional resources or funding $(12,13)$. VSM is a LEAN method that facilitates the analysis of current state or identifying areas of potential problems and development of a future state or creates solutions design for identified problems. VSM is the diagrammatical representation of the patient's journey through the system, and identifies the individual's steps, their value, duration interrelationship, process failures, staff-staff and staff-patient relationships (12). VSM has been successfully applied to bring the customers' voice which typically translates to three simple requirements - price, quality and delivery in initiating healthcare changes. These techniques have also been widely used in reducing wait times in emergency services (14). There is limited exploration of these techniques in chronic disease management.

There are challenges to applying VSM in the context of chronic disease management. Care delivery processes typically have high variability based on the level of individualization and population-specific care planning required especially in the management of complex conditions. Care delivery also takes place over a period of time with clinical steps and information flow largely dependent on the type of management and clinicians involved in care. As this initiative was part of a broader study, the review also required aligning with elements of the Chronic Care Model (15). This further required mapping the processes to key phases of care delivery, referral and triage processes, intake and care transition processes, and grouping clinical steps as routine and complex interventions (15). It was clear that a traditional manufacturing VSM methodology could not meet all the requirements of this initiative.

The outlined requirements are, however, somewhat similar to the consideration of VSM in office environments (15). There are differences in calculating waste or non-value added processes in manufacturing versus office environments $(16,17)$. Waste in transportation can be measured by calculating the time taken to move work in process from one work station to another (17). Office environments are more complex due to variability in consumption related to number of users, shared resources, time taken, and differences in arrival and departure times $(16,17)$. Calculating waste in manufacturing is achieved by estimating time taken to move work from workstation to workstation. However, office environments are more dynamic with a multitude of factors impacting work in process making it harder to track process time. These differences lead to differences in calculation of lead time in the two environments. In an office setting, lead time is measured from the time work is made available to a team or person to the time it is available to next person while in manufacturing demand drives the lead time (16-18). Based on the above, office setting type VSM review makes it more suitable for the current review of wait times in a complex chronic care management setting. As described earlier, the review included process steps in phases of care delivery such as at referral, intake, care transitions, discharge and rereferral and clinical steps in care such as routine care, complex care, self-management and functional health management supports, and community care and supports (12-15). A modified VSM was developed and applied in our study based on methods used in office VSM.

\section{Problem statement and research question}

Based on the above, the broader research problem and question is how to effectively apply a modified VSM approach in the context of complex chronic care management to reduce wait times to care.

\section{Study objective}

Towards the research question identified, the study steps included applying a modified VSM approach to reduce wait times to care, improve access, engage patients in the transformations and care processes, and optimize experience.

\section{Methods}

A case study approach was applied selecting a service that offered care for complex chronic conditions and where wait times to care were very high.

\section{Overview of the service and problem statement}

Integrated Chronic Care Service (ICCS) in PHC, Capital Health, sees close to 10,000 patient visits each year (19). Individuals have complex medical conditions, multiple chronic conditions, no diagnosis, overlapping mental health conditions and are typically high users of the system. Recent trends in our patient population show prevailing comorbidities in younger demographics (18-25 years). Due to the complexity of the patient population and urgency in needs, reducing wait times is a very important consideration for this team and the service. 
Individuals on the wait list have waited up to 24 months in the past and more recently up to 13 months to receive care. While they are waiting, individuals struggle from significant impacts to their health with many unnecessary and redundant tests being conducted during this waiting period. A study published by our group showed moderate reduction in physician and specialists visits following intervention at ICCS (20). Even this moderate change translates to savings to the healthcare system from a group that would otherwise be high consumers of healthcare services.

Nonetheless, upon entering our program, there are still wait times to individual components of their care. Recognizing the importance of these wait times to individuals and their care experiences and consequently the cost of not responding to this need in a timely manner, the ICCS applied a novel customer value-based approach (value stream mapping) to reduce wait times to care.

Several observations over a two-year period led to identification of the challenges related to wait times to care. These included high no show rate, feedback from patients and physicians about wait times, and lack of engagement and voice for patients in care delivery processes.

\section{Study procedure}

Figure 1 shows the study steps. The current state review of the service included patient surveys and interviews, physician surveys and interviews, interviews with care team members, administrative data and conducting the VSM of the processes. Patients and care team members reviewed the current state map to identify areas of concerns to develop the future state map with changes to the process.

Patient and referring physician engagement to assess current state

We applied a qualitative approach that included surveys and semi-structured interviews with current patients, patients on waitlist and referring physicans to assess the current state of care delivery. We wanted to understand all the areas of concerns or opportunities for progress as improving wait times requires creating cycles of improvement or Kaizen (LEAN terminology) throughout the care delivery processes (16).

\section{Surveys}

The Patient Assessment of Chronic Illness Care (PACIC) is a survey that gathers patient perspectives of care (21). This

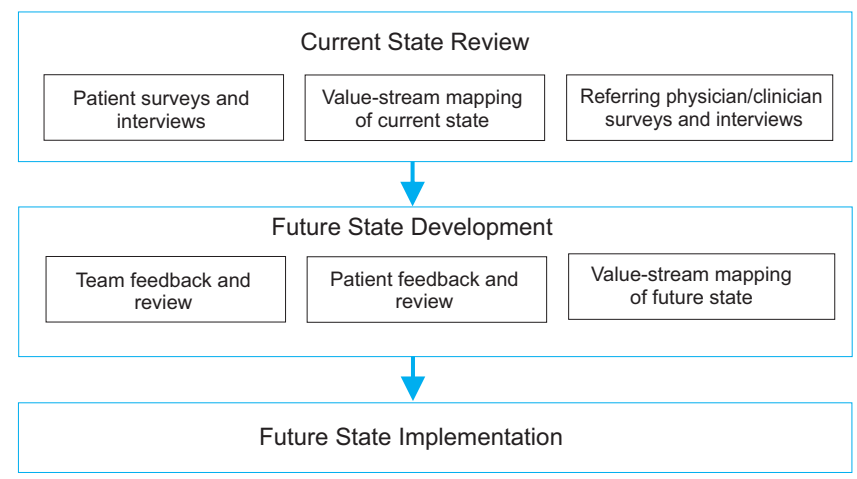

Figure 1. Study methodology. was administered to all patients of ICCS at transitions of care. In this 20-item questionnaire, patients rank their care from $1=$ almost never to $5=$ almost always. The ranking indicates if a required element of chronic disease care such as patient activation is always present (score of 5) or never present (score of 1). So, higher scores indicate that an aspect of quality chronic illness care is consistently present in the care delivery process.

The Referring Physician Satisfaction Survey was administered to referring physicians from ICCS to understand satisfaction with regards to the following: wait times, referral, intake, intervention, care transition and follow up processes (22).

\section{Semi-structured interviews}

Patients were also recruited to participate in semi-structured interviews to provide further opportunity for feedback on the emerging results from PACIC. Qualitative data was analyzed using framework methodology to identify how participants describe the various aspects of the challenges (23). The 5 stages of framework analysis was followed to gain an understanding in relation to the following: referral process, registration protocols, intake process, effectiveness of the intervention, care transitions, follow-up after discharge, and finally patient and referring physician engagement processes during intervention and self-management supports.

Referring physicians were also recruited to participate in semi-structured interviews to provide further opportunity for feedback on the emerging results from the Referring Physician Satisfaction Survey. The framework method was applied for analysis of themes from the interviews as described in the patient interview section.

\section{Modified Value Stream Mapping (VSM)}

The modifications included applying office environment VSM protocols, calculating lead time as time taken to process work in different phases of care delivery and routine and complex interventions, process time for clinical steps and interventions, and use of a bar graph to show ratio of value added to non value added steps.

\section{Current state review}

Intervention included review of current state data by ICCS care team, patient representatives and formal leads of the initiative. The current state data included feedback from surveys, interviews, VSM, and feedback from ICCS care team and patient representatives.

Table 1 shows results from PACIC data highlighting improvement areas related to patient engagement and follow up care. Patients do not feel engaged in care and require better support at follow up and discharge as indicated by the results. Results from the referring physician survey $(n=10)$ are shown in Table 2. The results demonstrate reduced satisfaction at initial consult and at care transitions in the care delivery processes.

Table 3 shows sample feedback obtained in semi-structured interviews from key stakeholder groups. Broad themes of focus retrieved from interviews include improving wait times to care at intake, more specific interventions, improve processes at intake and discharge, reduce distress felt by wait list individuals by offering various types of supports, and 
Table 1. PACIC

\begin{tabular}{lc}
\hline & $\begin{array}{c}\text { Mean value (SD) } \\
\text { Maximum score= 5 } \\
\mathbf{n}=\mathbf{3 0}\end{array}$ \\
\hline Patient activation & $3.8(1.1)$ \\
Delivery system design/decision support & $4.2(1.2)$ \\
Goal setting/tailoring & $4.3(1.1)$ \\
Problem solving/contextual & $4.4(1.3)$ \\
Follow up/coordination & $3.1(1.1)$ \\
\hline
\end{tabular}

$\mathrm{PACIC}=$ Patient Assessment of Chronic Illness Care

Table 2. Referring Physician Satisfaction Survey

\begin{tabular}{lc}
\hline & $\begin{array}{c}\text { Mean value (SD) } \\
\text { Maximum score= 5 } \\
\mathrm{n}=\mathbf{1 0}\end{array}$ \\
\hline Initial consultation & $3.2(1.3)$ \\
Referral process & $4.1(1.1)$ \\
Treatment & $4.2(1.2)$ \\
Care transition & $2.4(1.1)$ \\
\hline
\end{tabular}

engaging patients in their needs.

Process before included all wait listed individuals being seen in an individual appointment by physician or nurse practitioner followed by appointment with a care coordinator. Upon completion of these individual appointments, patients were scheduled to participate in group interventions targeted to achieve education and behaviour modification targets for this population. Concurrently, patients were triaged into relevant individual care intervention processes based on identified areas of concerns.

Based on the current state mapping, the following were observed as opportunities for improvement shown in Figure 2: individuals appointments for new patients were a source of bottle neck, triage criteria for urgent patients did not have the required level of response, patient readiness to engage is care pathways was not appropriately assessed, wait list patients did not receive any support while waiting to receive care, high no shows to new patient, dietary and psychotherapy
Table 3. Interviews with various stakeholders

\begin{tabular}{|c|c|}
\hline Interviews & Sample feedback \\
\hline $\begin{array}{l}\text { Patients } \\
(n=4)\end{array}$ & $\begin{array}{l}\text { I am still a patient of your clinic because I am still waiting } \\
\text { to access your psychologist for a year. } \\
\text { Long wait times to see your psychologist. } \\
\text { Why do I have to wait so long to access your group } \\
\text { programs. } \\
\text { I do not want to be discharged because I have to again } \\
\text { wait a long time to receive care. } \\
\text { My opinion is not included in my care. }\end{array}$ \\
\hline $\begin{array}{l}\text { Referring } \\
\text { physicians } \\
(n=5)\end{array}$ & $\begin{array}{l}\text { No longer interested in this referral. } \\
\text { Patient is receiving care elsewhere. } \\
\text { Long wait times for care. } \\
\text { Initial consult process is not effective. } \\
\text { Discharge and follow up process is not effective. }\end{array}$ \\
\hline $\begin{array}{l}\text { Wait list } \\
\text { individuals } \\
(n=5)\end{array}$ & $\begin{array}{l}\text { Improve access to care, reduce wait times. } \\
\text { Waiting to receive care is not helpful, can anything be } \\
\text { done to change this. } \\
\text { Distress of managing my condition is increasing while I } \\
\text { wait. } \\
\text { Unable to function. } \\
\text { I just want to know my diagnosis. } \\
\text { I would benefit from receiving some education and } \\
\text { support while I wait. }\end{array}$ \\
\hline
\end{tabular}

appointments, wait times to group interventions, intake to discharge rate was disproportional, and wait times for new patients almost equal to duration of care.

\section{Future state development}

Based on the in-depth review conducted in current state, future state improvements were identified as shown in Table 4. Future state changes are shown in Figure 3 and described in detail below.

\section{Engaging individuals on wait list}

A series of new patient group intervention appointments targeting education, behaviour change intervention, care coordination and medical education intervention have been introduced. These appointments cover a range of topics based on feedback received from wait list individuals and patients. Sessions are offered in multiple ways such as onsite, telehealth, telephone, as group and 1:1 appointments

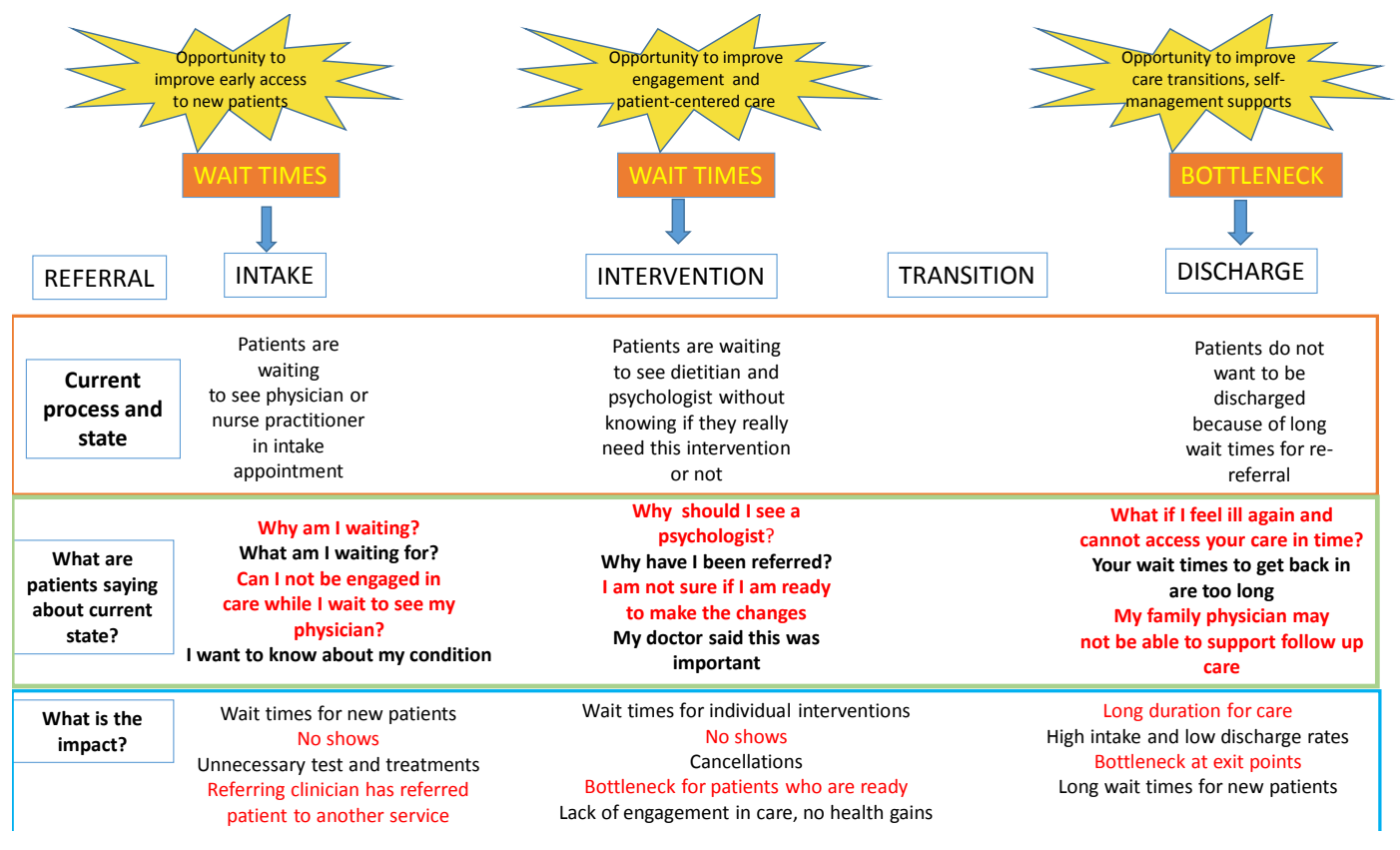

Figure 2. Challenges for patients and process in the current state. 
Table 4. Opportunities identified for future state improvements

\begin{tabular}{|c|c|c|}
\hline \multirow{2}{*}{ Waste type } & \multicolumn{2}{|r|}{ Overall opportunity } \\
\hline & Traditional VSM & Modified VSM \\
\hline \multirow[t]{2}{*}{ Transportation } & $\begin{array}{l}\text { Moving product between processes does not add } \\
\text { value to the product. Excessive movements and } \\
\text { handlings can cause damages and can lead to } \\
\text { reduction in quality. }\end{array}$ & $\begin{array}{l}\text { Individuals on wait list for ICCS are moving to other care providers and } \\
\text { treatment which could lead to poor quality of care as they may not be } \\
\text { appropriate or redundant. }\end{array}$ \\
\hline & \multicolumn{2}{|r|}{ Opportunity } \\
\hline Excess inventory & \multicolumn{2}{|c|}{$\begin{array}{l}\text { Excess inventory uses valuable floor space and hides problems related to process incapability. } \\
\text { Patients are not being discharged due to various reasons such as not receiving proper support at discharge, long wait times to re- } \\
\text { enter ICCS. They hold up space by using time of clinicians and less spots for new patients. }\end{array}$} \\
\hline Excess motion & \multicolumn{2}{|c|}{$\begin{array}{l}\text { Any motion that employee has to perform which does not add value to the product and is considered unnecessary or excess } \\
\text { motion. } \\
\text { Offering treatment to patients when they are not engaged in care such as dietary or psychological interventions. }\end{array}$} \\
\hline Waiting & \multicolumn{2}{|c|}{$\begin{array}{l}\text { Whenever goods are not being processed, they are waiting. } \\
\text { Wait list patients, patients waiting to receive dietary and psychology interventions. They are being held by processes such as intake } \\
\text { appointment with physician, offering psychology or dietary interventions to patients who are not ready to receive care. }\end{array}$} \\
\hline Over production & \multicolumn{2}{|c|}{$\begin{array}{l}\text { Producing more than the customer demand requires. } \\
\text { Holding patients with processes more than required by the patients. }\end{array}$} \\
\hline Over processing & \multicolumn{2}{|c|}{$\begin{array}{l}\text { Taking unneeded steps to process the parts. } \\
\text { Offering care to patients who are not ready or may not require recommended care, holding patients at discharge by offering care } \\
\text { not relevant versus taking steps to improve readiness and confidence for discharge. }\end{array}$} \\
\hline
\end{tabular}

VSM= Value Stream Mapping; ICCS= Integrated Chronic Care Service.

\begin{tabular}{|c|c|c|c|c|}
\hline & NEW PROCESS & \multicolumn{2}{|c|}{ NEW PROCESS } & NEW PROCESS \\
\hline REFERRAL & INTAKE & INTERVENTION & TRANSITION & DISCHARGE \\
\hline $\begin{array}{l}\text { Future } \\
\text { process and } \\
\text { state }\end{array}$ & $\begin{array}{l}\text { Soon after referral, patients see } \\
\text { care coordinator and nurse in group } \\
\text { and individual interventions, hope } \\
\text { and needs form } \\
\text { - Care info, info on medical } \\
\text { condition, assessment of needs }\end{array}$ & \multicolumn{2}{|c|}{$\begin{array}{c}\text { Patients express their readiness for } \\
\text { psychosocial and dietary } \\
\text { intervention through care } \\
\text { coordinator and hope and needs } \\
\text { form } \\
\text { Group treatments are offered first }\end{array}$} & $\begin{array}{l}\text { Patients readiness for } \\
\text { discharge is assessed, new } \\
\text { re-referral process with LPN } \\
\text { triaging patients to timely } \\
\text { and relevant care without } \\
\text { wait times }\end{array}$ \\
\hline $\begin{array}{l}\text { What are } \\
\text { patients saying } \\
\text { about future } \\
\text { state? }\end{array}$ & $\begin{array}{l}\text { We are glad not to wait } \\
\text { We can learn about ICCS care } \\
\text { Understand your approach } \\
\text { Tell you our specific needs } \\
\text { Help develop supports in the } \\
\text { community }\end{array}$ & \multicolumn{2}{|c|}{$\begin{array}{l}\text { I have a choice to express } \\
\text { my needs and tell you } \\
\text { about my readiness. } \\
\text { I may not be ready for this } \\
\text { treatment yet. } \\
\text { I would like to learn more in } \\
\text { a group intervention }\end{array}$} & $\begin{array}{l}\text { I feel confident about being } \\
\text { discharged } \\
\text { My readiness is being assessed } \\
\text { New re-referral process is } \\
\text { helpful }\end{array}$ \\
\hline $\begin{array}{l}\text { What is the } \\
\text { impact? }\end{array}$ & $\begin{array}{c}\text { No wait times to care } \\
\text { Patients are better engaged and better } \\
\text { informed } \\
\text { Community supports are better } \\
\text { aligned, team can focus on specific } \\
\text { needs }\end{array}$ & \multicolumn{2}{|c|}{$\begin{array}{c}\text { No wait times to care } \\
\text { Timely psychosocial and dietary } \\
\text { interventions for those ready to receive } \\
\text { care } \\
\text { Better engagement in care }\end{array}$} & $\begin{array}{c}\text { Discharge rates improved } \\
\text { Duration of care average at } 6 \text { months } \\
\text { versus } 2+\text { years }\end{array}$ \\
\hline
\end{tabular}

Figure 3. Future state process.

to improve access for patients travelling distance, working or with other limitations. Patients that are no shows to the orientation session are given a second option to attend and if they do not accept this, a letter to the referring physician is sent indicating the same and that their patient can be referred at any time given that the wait times are small.

\section{Patient engagement in care}

A survey to engage patients early in their care called the Hopes and Needs survey has been developed and implemented at each of the new patient sessions. This allows new patients to select their care pathways based on their readiness to receive care.

\section{Process changes for individual treatments}

Process changes for individual treatment modalities that had wait times to care includes introducing group interventions to aid early response and access in addition to supporting readiness for those that require further individualized supports. In addition, patients are allowed self-selection of care processes based on readiness using the Hopes and Needs survey.

\section{Process change for transition and discharge patients}

This is a work in progress for the ICCS team which is creating better supports for patients in the community and follow up care with their family physicians. Community resources, toolkit for physicians to manage complex patients and better communication strategies at discharge are some of the process changes that are being developed.

Results

Wait times for new patients have significantly reduced from approximately 13 months in 2012 to 2 months in 2014 as 


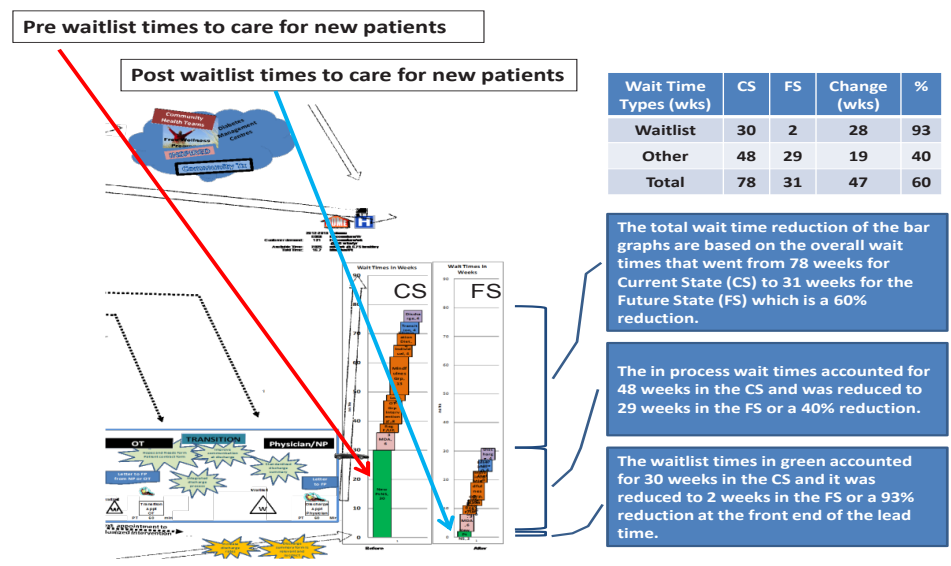

Figure 4. Value-stream map showing post reduction in new patient wait times - due to process change at intake.

shown in the Figure 4. There will be no wait times for new patients in 2015 to receive ICCS intervention.

The green stacks (the lower stacks in both the current and future state) on the bar graphs in Figure 4 show a drastic reduction of wait times from the waitlist (from 30 weeks to 2 weeks), but the graph also shows that the remaining wait times (the remainder of the stacks that are not green) was reduced by about $40 \%$ (from 48 to 29 weeks).

The scales of both bar graphs being equal ( 0 to 90 weeks) reflects this reduction of all the non green items which was accomplished by streamlining the care pathways. The reduction in wait time is shown in the table within Figure 4 above and is explained in corresponding boxes. The processes changes to reduce the "Other" wait time from Figure 4 are described later in this section.

The care pathway that a patient may follow from referral to discharge is complex. Typically office setting VSM tends to be complex as well. In those cases, appropriate segments of the complex paths are selected to baseline the current state. Because of the complexities of the care paths opportunities that patients may follow in our case, a typical pathways segment was calculated based on the average of the types of intervention occurring for all the types of interventions. These are indicated by the red blocks of the time lines in Figure 5 below.

The actual process time for a single visit through all the pathways for a specific care path segment was about 7 days only and is not included in the stacks as it would show as a line.

Figures 5 and 6 show VSM changes and run-time graph postintervention for new patients.

Wait times for individual components of care that were an issue have improved significantly through relevant process related improvement cycles that have been applied as shown in the Table 5.

A number of approaches of relevance were developed to support this process. These include introducing a simple one-page Hope and Needs survey tool to allow patients to self-select their readiness to various types of care. In addition, having the care coordinator better support patient's navigational needs at early stages of care and at relevant points in care delivery to ensure appropriates of care and managing referrals have all contributed to improved wait times to care. Previously, not including patients in this process resulted in high no show rates for these appointments.

Discharge rates for ICCS have improved significantly $>10 \%$ since introduction of process changes. Referral rates increased by $20 \%$ since 2013 .

\section{Hope and Needs survey - providing voice to the patients}

The Hope and Needs survey created a voice for patients to provide feedback on their care needs, communication of their

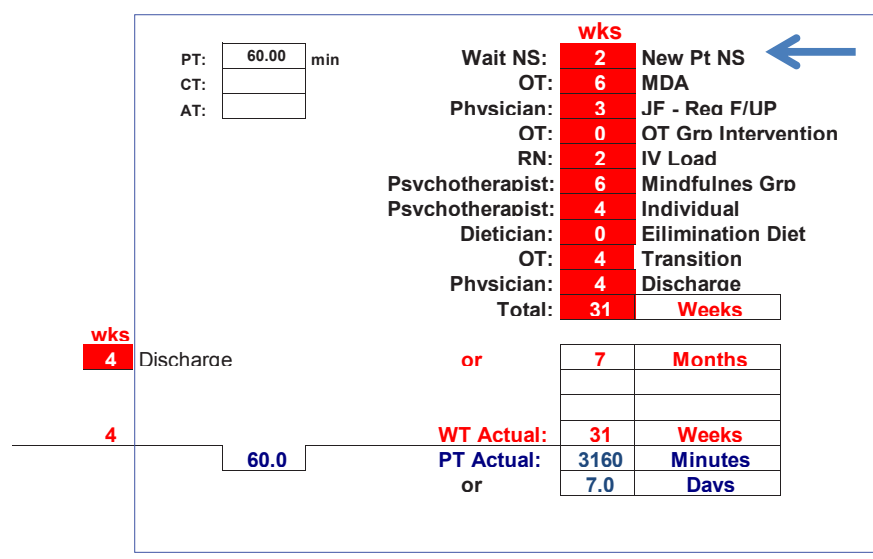

Change in new patient wait times from 30 weeks to 2 weeks

Figure 5. Shows the care path segments that were used to calculate the total wait time. 
Table 5. Wait times to individual interventions

\begin{tabular}{|c|c|c|c|}
\hline $\begin{array}{l}\text { Individual treatment } \\
\text { components at ICCS }\end{array}$ & $\begin{array}{l}\text { Wait times before } \\
\text { intervention }\end{array}$ & $\begin{array}{l}\text { Wait times after } \\
\text { intervention }\end{array}$ & Process changes \\
\hline Dietary intervention & $>3$ months & 1 or 2 weeks & $\begin{array}{l}\text { Offering intervention in small groups on specific topics such as } \\
\text { elimination diet } \\
\text { Hopes and Needs survey tool for self-selection based on readiness }\end{array}$ \\
\hline Psychotherapy & $>12$ months & 3-4 weeks & $\begin{array}{l}\text { Group intervention } \\
\text { Hopes and Needs survey tool for self-selection based on readiness } \\
\text { Screening at intake for appropriateness }\end{array}$ \\
\hline $\begin{array}{l}\text { Medical intervention for } \\
\text { priority intervention }\end{array}$ & $>6$ weeks & Same week & $\begin{array}{l}\text { Take an existing space in weekly appointment schedule specifically } \\
\text { allocated to accommodate this need }\end{array}$ \\
\hline $\begin{array}{l}\text { Individuals that need only a } \\
\text { medical appointment without } \\
\text { team-based care }\end{array}$ & $>13$ months & $1-2$ weeks & Hopes and Needs survey tool for self-selection based on readiness \\
\hline
\end{tabular}

ICCS $=$ Integrated Chronic Care Service.

self-management needs, identify if they need their medical management should be addressed first, and readiness of patients to engage in ICCS care.

\section{Patient satisfaction feedback}

Following implementation of new processes, patients involved in the current state reviewed future state processes and offered feedback. Sample feedback is shown Table 6.

\section{Discussion and Conclusion}

Wait times to care specifically for complex conditions can have significant impacts at various levels, leading to physical and psychological distress for individuals waiting to receive care. Additionally, wait times have created blocks at various points in the healthcare system related to inappropriate referrals, unnecessary or repeat tests and interventions with financial impacts to the individual and the system. Individuals with multimorbidities (more than 3 chronic conditions) bring a further challenge in that they require timely, relevant and coordinated care to address increasingly complex clinical

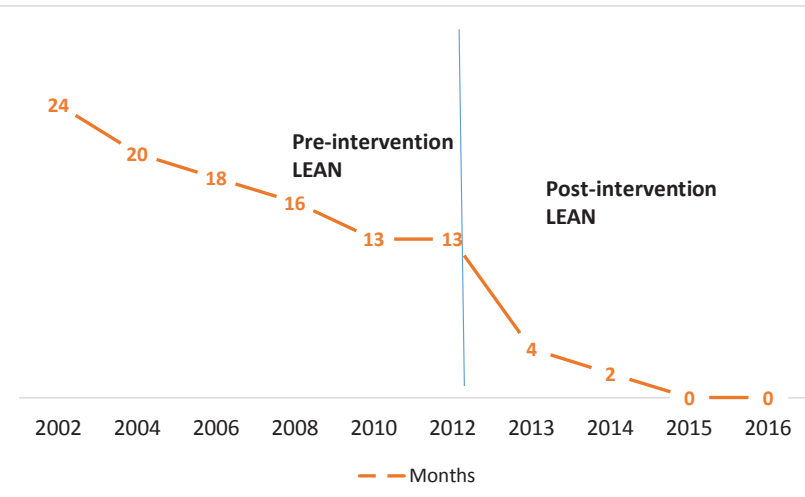

Figure 6. Graph showing changes to wait times post intervention.

Table 6. Feedback from patients post intervention

"It is good to know that we have a voice" - patient representative
"I have a whole team in the community and I do not want to engage your
multidisciplinary team as well. Just provide me a diagnosis and I can be
discharged. Thanks for listening".
"I am glad I do not have to wait for long to receive my care".
"Thanks for listening to us and making changes that are meaningful".

situations (24).

However, applying this process to chronic disease management requires an adaptation in the VSM method based on office environments versus manufacturing and based on work process related to chronic care model elements (16-18).

In the initiative, care and access for multimorbidities and wait times were improved through a modified VSM. A series of improvement cycles were identified concurrently to impact overall flow and wait times to care. Using several improvement cycles (Kaizen) as outlined in this paper, ICCS was able to reduce wait times to care from greater than 13 months to no wait times in 2015. Quality of the changed process and impact on health outcomes will be measured over time. However, in this paper some preliminary results of patient experience results have been presented. In addition, other improvement cycles of relevance to this initiative currently in progress such as process for discharge patients have been discussed. Listening to and actively engaging patients in an appropriate manner can have significant impacts to flow processes in addition to an improvement in the patient experience. Introducing a simple tool in the form of a Hope and Needs survey allowing patients to self select their care based on readiness seemed to make a significant difference to wait times as demonstrated in this initiative.

Health outcomes and cost implication are being monitored to further study the effect of the process improvements. Having a LEAN consultant to conduct the current state review and future state development was an advantage to this initiative as it reduced provider or team bias in the review of the process. Including patients in the review and feedback was important to ensure patient perspectives in the future state changes to process.

While assessing the problem for new patients, the team had to consider the care flow processes for the entire delivery from referral to discharge knowing any changes made during the process at any point in the delivery would have to be concurrently mapped to other points of care delivery in order to avoid shifting bottle necks to other points of care delivery. By eliminating waste from several points in our care delivery, the team was able to reduce wait times for their patients. Many of these changes were minor and had minimal to no impact on personnel or resources.

The LEAN method applied in this initiative created a structured process to analyze based on customer perspectives 
while improving care strategies that improve value for the customer. By applying a customer value-based approach, the team was able to include patient perspectives in implementing value added processes and improve engagement in care delivery while reducing wait times with no additional costs to make changes to care delivery.

\section{Ethical issues}

The study was approved by the research ethics committees at the Nova Scotia Health Authority, Halifax, NS, Canada.

\section{Competing interests}

The authors declare that they have no competing interests.

\section{Authors' contributions}

$T S$, LE, MD, RD, and GB were responsible for study concept and design. TS, $M D, R D$, and $M D h$ were responsible for data gathering and data management process. TS, MDh, and MD performed data analysis. TS, MD, MDh, RD, and LE produced interpretations of findings. TS, MD, and MDh drafted the manuscript and all authors provided important feedback and approved the final version.

\section{Authors' affiliations}

${ }^{1}$ Integrated Chronic Care Service, Primary Health Care, Nova Scotia Health Authority, Halifax, NS, Canada. 'Dalhousie University, Halifax, NS, Canada. ${ }^{3}$ Primary Health Care, Nova Scotia Health Authority, Halifax, NS, Canada. ${ }^{4}$ Performance Excellence, Nova Scotia Health Authority, Halifax, NS, Canada.

\section{References}

1. Tinetti ME, Fried TR, Boyd CM. Designing health care for the most common chronic condition - multimorbidity. JAMA 2012; 307: 2493-4. doi: 10.1001/jama.2012.5265

2. Canadian Institute for Health Information. All-Cause Readmission to Acute Care and Return to the Emergency Department. Ottawa, Ont., Canada; 2012. [updated 2012 June 14; cited 2014 Nov 18]. Available from: https://secure.cihi.ca/free_products/ Readmission_to_acutecare_en.pdf

3. Fortin M, Bravo G, Hudon C, Vanasse A, Lapointe L. Prevalence of multimorbidity among adults seen in family practice. Ann Fam Med 2005; 3: 223-8. doi: 10.1370/afm.272

4. Glynn LG, Valderas JM, Healy P, Burke E, Newell J, Gillespie $\mathrm{P}$, et al. The prevalence of multimorbidity in primary care and its effect on health care utilization and cost. J Fam Pract 2011; 28 : 516-23. doi: 10.1093/fampra/cmr013

5. Capital Health. Primary Health Care. Annual Report on multimorbidities and chronic conditions. Annual Report; 2012. [updated 2012 Oct 1; cited 2014 Nov 24]. Available from: http:// www.cdha.nshealth.ca/primary-health-care/documents

6. Statistics Canada. Canadian Community Health Survey, Cycle 3.1. [Public Use Microdata File (PUMF) User Guide] ; 2005 Statistics Canada, Ottawa, Ont., Canada. [updated 2006 June; cited 2014 Nov 1]. Available from: http://www23.statcan.gc.ca/ imdb-bmdi/pub/document/3226_D7_T9_V3-eng.pdf

7. Statistics Canada. CANSIM Table 326-0021 - Consumer price index (CPI) - health care costs, 2005 basket, annual; 2009b Statistics Canada, Ottawa, Ont., Canada. [updated 2009; cited 2014 Nov 1]. Available from: http://www.statcan.gc.ca/pub/11621-m/11-621-m2010084-eng.pdf

8. Statistics Canada. CANSIM Table 051-001: Estimates of population, by age group and sex for July 1, Canada, provinces and territories, annual (persons); 2012 Statistics Canada Ottawa, Ont., Canada. [updated 2014 Sept 26; cited 2014 Nov 1]. Available from: http://www.statcan.gc.ca/tables-tableaux/ sum-som/l01/cst01/demo31a-eng.htm

9. Capital Health. The Promise of Primary Health Care: The Community Master Plan Working Document. Capital Health; 2010. [updated 2012 Aug 29; cited 2014 Nov 12]. Available from: http://www.cdha.nshealth.ca/primary-health-care/communitymaster-plan

10. Sampalli T, Christian E, Edwards L, Dhir M, Kohler G, Lisa $B$, et al. A patient-centered redesign framework to support system-level process changes for multimorbidities and chronic conditions. Healthcare Q (In Review) 2014.

11. Sampalli T, Christian E, Edwards LA. A corridor' approach to support system-level transformations for chronic conditions. Healthcare Q (In Review) 2014.

12. Trebble TM, Hansi N, Hydes T, Smith MA, Baker M. Process mapping the patient journey: an introduction. BMJ 2010; 341: c4078. doi: 10.1136/bmp.c4078

13. Trebble TM, Hydes T. Redesigning services around patients and their doctors: the continuous relevance of lean thinking transformation. Clin Med 2011; 11: 308-10. doi: 10.7861/ clinmedicine.11-4-308

14. Eller AJ. Rapid assessment and disposition: applying LEAN in the emergency department. J Healthc Qual 2009; 31: 17-22. doi: 10.1111/j.1945-1474.2009.00026.x

15. Barr VJ, Robinson S, Marin-Link B, Underhill L, Dotts A, Ravensdale $D$, et al. The expanded chronic care model: An integration of concepts and strategies from population health promotion and the chronic care model. Hosp Q 2003; 7: 73-82.

16. Chen JC, Cox RA. Value stream management for lean office: a case study. American Journal of Industrial and Business Management 2012; 2: 17-29.

17. Bushell S, Shelest B. Discovering lean thinking at progressive healthcare. The Journal for Quality and Participation 2002; 25: 20-5.

18. Lummus RR, Vokurka J, Rodeghiero B. Improving quality through Value Stream Mapping: a case study of a physician's clinic. Total Quality Management 2006; 17: 1063-75. doi: 10.1080/14783360600748091

19. Sampalli T, Fox RA, Dickson R, Fox J. Proposed model of integrated care to improve health outcomes for individuals with multimorbidities. Patient Prefer Adherence 2012; 6: 757-64. doi: 10.2147/ppa.S35201

20. Fox RA, Joffres MR, Sampalli T, Casey J. The impact of a multidisciplinary, holistic approach to management of patients diagnosed with Multiple Chemical Sensitivity on healthcare utilization costs: An observational study. J Altern Complement Med 2007; 13: 223-30. doi: 10.1089/acm.2006.60

21. Glasgow RE, Wagner E, Schaefer J, Mahoney L, Reid R, Greene S. Development and validation of the Patient Assessment of Chronic IIIness Care (PACIC). Med Care 2005; 43: 436-44.

22. Rosenbach M, Kagan S, Leventhal S. Dermatology urgent care clinic: a survey of referring physician satisfaction. J Am Acad Dermatol 2013; 69: 1067-9. doi: 10.1016/j.jaad.2013.08.018

23. Braun V, Clarke V. Using thematic analysis in psychology. Qual Res Psychol 2006; 3: 77-101.

24. Bayliss E, Edwards A, Steiner J, Main D. Processes of care desired by elderly patients with multimorbidities. Fam Pract 2008; 25: 287-93. doi: 10.1093/fampra/cmn040 